\title{
Assessment of the elastic response of shale using multiscale mechanical testing and homogenisation
}

\author{
Mohamed Rouainia ${ }^{1, *}$, Majid Goodarzi ${ }^{2}$, Tom Charlton ${ }^{1}$, Andrew Aplin ${ }^{3}$, and Pablo Cubillas ${ }^{3}$ \\ ${ }^{1}$ School of Engineering, Newcastle University, United Kingdom \\ ${ }^{2}$ MARUM, Universität Bremen, Germany \\ ${ }^{3}$ Department of Earth Sciences, Durham University, United Kingdom
}

\begin{abstract}
Robust geomechanical characterisation of shale reservoirs is necessary for safe and economic resource exploitation but there is still a lack of mechanical data on well-characterised shale, partly due to the difficulties of obtaining high quality core samples for laboratory testing. The composition of shale also presents challenges when attempting to constrain the mechanical response. Multi-scale homogenisation techniques have recently been used to predict the macroscopic behaviour of shales based on quantitative mineralogical descriptions. However, there is a considerable amount of uncertainty associated with some key inputs into these homogenisation schemes. In particular, the organic matter of shale encompasses a range of scales, from nanometre to micrometre-size material, and its mechanical properties are not well understood. Here, PeakForce Quantitative Nanomechanical Mapping (PF-QNM), a recently developed form of atomic force microscopy (AFM), is combined with nanoindentation testing to characterise the mechanical response of the organic matter and clay phases of Posidonia shale from north-west Germany. The nanoscale testing revealed a clear peak in the histograms of the reduced elastic modulus, which can be attributed to kerogen in the shale matrix. Upscaling of the mechanical properties through homogenisation showed a reasonable prediction when compared with experimental data, including capturing the inherent anisotropy of the shale response. The influence of factors such as the volume fraction of silt inclusions and the applicability of different homogenisation formulations warrant further investigation.
\end{abstract}

\section{Introduction}

Many experimental studies have observed a strong correlation between the composition of mudrocks and their macroscopic response and yield strength [1, 2]. These observations suggest that the overall mechanical behaviour of these natural nano-composite materials originates from their different constituents and microstructure. Therefore, obtaining data on the mechanical response of mudrocks at a small scale could pave the way to better understanding when predicting the macroscale behaviour. In addition, technical challenges in characterising the mechanical behaviour of shale formations at macroscale have drawn more attention to micromechanical studies. For example, good quality core samples suitable for conventional rock mechanics experiments are expensive to retrieve [3]. Furthermore, the heterogeneity of shales on many scales [4] makes it difficult to extrapolate the data obtained from a small number of core samples to the whole shale deposit [5]. Well sonic $\operatorname{logs}$ are incapable of directly measuring properties in the direction parallel to the wellbore and so the anisotropy of the shale rocks is particularly challenging to characterise [6].

The constituents of shale range in size from a few microns to a few nanometres. Some of these components, such as quartz, calcite and pyrite grains, can be found at a larger scale which makes it possible to use conventional rock mechanics tests to extract their mechanical properties. On the other hand, organic matter is present in the intergranular pore space and its mechanical behaviour is poorly understood. The same problem also exists for the solid unit of porous clay which makes it almost impossible to conduct direct mechanical measurements. Most of the studies to date have used nanoindentation testing to observe the micromechanical response of shale rocks. The statistical analysis of the extracted data, with a resolution of a few microns, can often only define the shale microstructure as a soft and a stiff phase. The soft phase can be attributed to the mixture of organic matter and porous clay. However, the hard phase is related to the response of all types of silt mineral grains in the shale microstructure $[7,8]$. Some researchers have also tried to target a big piece of organic matter and conduct nanoindentation tests [9-11]. This measurement might be inaccurate because the organic matter is not large enough to satisfy the assumption of an infinite half-space, which is used in the derivation of the equations for elastic properties in the indentation test.

In this paper, several shale samples will be analysed with the objective of using multi-scale mechanical testing to constrain the properties of the constituents, in particular

\footnotetext{
${ }^{*}$ Corresponding author: Mohamed.Rouainia@newcastle.ac.uk
} 
the organic matter, and upscaling the elastic response using homogenisation techniques. The samples are initially characterised in terms of mineralogy, porosity and total organic carbon (TOC). Then, a comprehensive study on the elastic response at nanometre-scale will be conducted using PeakForce QNM. Nanoindentation tests are performed on the samples in both parallel and perpendicular directions to the bedding planes. The loaddisplacement curve for each indent is extracted and used to determine the elastic moduli and anisotropy. Finally, a homogenisation scheme is used to obtain the macroscale elastic response and compare against experimental measurements.

\section{Sample description}

For this study, a set of samples from the Posidonia shale was selected with different maturity levels and silt inclusion fractions. The Posidonia shale formation from the Lower Saxony Basin is a fine grained calcareous shale that contains high amounts of organic matter (type II kerogen). This formation is among the earliest hydrocarbon-producing basins in Europe and is now considered one of the most important source rocks in Western Europe [12]. Here, three samples were selected from different boreholes known as Wickensen (WIC), Harderode (HAR) and Haddessen (HAD), located in the Hils half-graben, northern Germany.

The mineralogical composition was determined by Mathia et al. [13] and is summarised in Table 1. Note that a range of samples from each borehole were characterised and average values are shown. Typical grain densities [14] have been used to convert to volume fractions. The kerogen volume fraction is estimated using the empirical relationship [15]:

$$
\begin{gathered}
V_{k}=\frac{T O C \rho_{b}}{C_{k} \rho_{k}} \\
\text { with } \rho_{b}=(1-\phi) \rho_{k}
\end{gathered}
$$

where $V_{k}$ is the volumetric kerogen content, TOC is the wt $\%$ of kerogen, $C_{k}$ is an empirical coefficient that depends on maturity level, $p_{k}$ and $p_{b}$ are respectively the grain and bulk densities. The three samples have vitrinite reflectance $\left(\mathrm{R}_{\mathrm{o}}\right)$ values of $0.53 \%$ (WIC), $0.89 \%$ (HAR) and $1.45 \%$ (HAD) and are considered immature, mature and over-mature respectively. Appropriate values for Eq. (1) are taken from literature $[15,16]$. Mercury injection was also used in order to estimate the samples' porosity.
Table 1. Shale mineralogy in vol\%. Max and min values also indicated for kerogen and porosity.

\begin{tabular}{|c|c|c|c|}
\hline Composition & WIC & HAR & HAD \\
\hline Quartz & 9.4 & 12.2 & 9.8 \\
\hline Feldspar & 0.7 & 2.7 & 3.1 \\
\hline Calcite & 29.7 & 33.3 & 32.6 \\
\hline Dolomite & 0.2 & 2.0 & 1.6 \\
\hline Pyrite & 1.8 & 3.2 & 2.5 \\
\hline Clay & 23.6 & 25.8 & 23.6 \\
\hline Kerogen & $\begin{array}{c}23.3 \\
(15.8,31.2)\end{array}$ & $\begin{array}{c}16.9 \\
(13.4,20.2)\end{array}$ & $\begin{array}{c}15.4 \\
(11.4,16.7)\end{array}$ \\
\hline Porosity, $\phi$ & $\begin{array}{c}11.3 \\
(9.7,13.9)\end{array}$ & $\begin{array}{c}3.9 \\
(3.1,4.6)\end{array}$ & $\begin{array}{c}11.4 \\
(9.3,13.7)\end{array}$ \\
\hline
\end{tabular}

\section{Nano and microscale mechanical testing}

\subsection{Atomic Force Microscopy}

PeakForce Quantitative Nanomechanical Mapping (QNM) is an advanced mode of the conventional Atomic Force Microscopy (AFM) test, which enables the production of both topographical and mechanical maps of a sample surface [17]. The standard HOPG-12M was used for calibration, with values of $1 \mathrm{kHz}$ and $50-150 \mathrm{nN}$ selected for oscillation frequency and peak force respectively.

Sections were prepared perpendicular to the bedding plane to have a higher chance of encountering all constituent phases. Figure 1 shows the reduced modulus (E* or DMT) map for a target area of the organic-rich WIC sample.

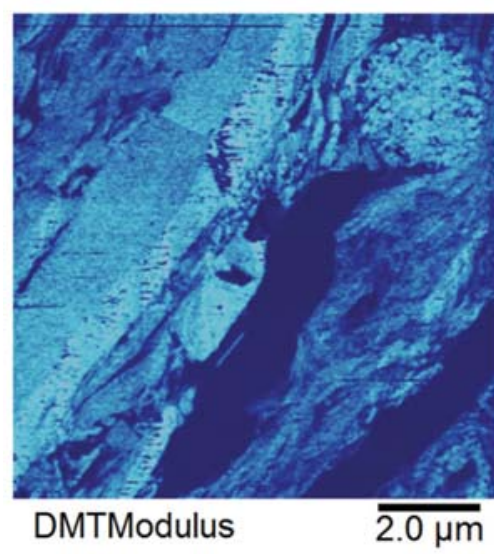

(b 1) $100.0 \mathrm{GPa}$

Figure 1. Reduced modulus map. 
For each target area, a histogram of the reduced modulus was plotted. The different soft and hard phases in the shale show as peaks in the histogram. A kernel density estimate was used to identify the peaks. Figure 2 presents the histogram of the target area shown previously. A clear peak is observed at low values of elastic modulus, which can be attributed to kerogen embedded in the shale microstructure. The peak occurs at a reduced modulus of $6.45 \mathrm{GPa}$, which corresponds to an elastic modulus of $5.9 \mathrm{GPa}$ if Poisson's ratio is assumed to be 0.3. A separate target area of the WIC sample showed a similar peak at $6.45 \mathrm{GPa}$, confirming the consistency of the measurements.

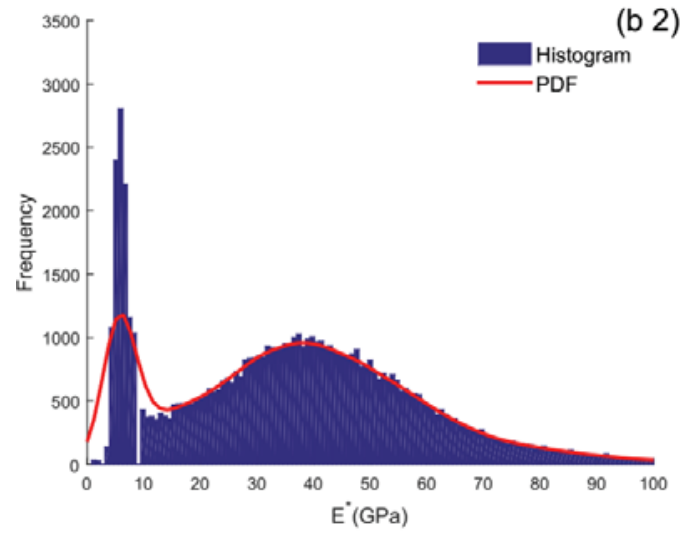

Figure 2. Histogram of reduced modulus measurements.

The elastic modulus values for kerogen acquired by AFM are shown in Table 2. Some difficulties were experienced in measuring the stiffness of organic matter in the HAD sample. The kerogen was trapped between silt inclusions and it proved impossible to extract a reliable measurement.

Table 2. Elastic properties of kerogen.

\begin{tabular}{|c|c|c|c|}
\hline Sample & Ro (\%) & E (GPa) & v \\
\hline WIC & 0.53 & 5.9 & 0.3 \\
\hline HAR & 0.89 & 10.35 & 0.3 \\
\hline
\end{tabular}

A wide range of elastic properties has been reported for organic matter in previous studies on a range of shale formations, which leads to uncertainties in the implementation of rock physics models. For instance, Zeszotarski et al. [9] performed nanoindentation tests on kerogen in Woodford shale. Isotropic behavior was observed and, given $v=0.3$, the elastic modulus was estimated to be $11.5 \mathrm{GPa}$. The same approach was adopted by [3, 11], who reported values of less than $2 \mathrm{GPa}$ for highly porous kerogen.

Vernik and Nur [18] used the thin-layer composite concept and found the mechanical properties of kerogen as isotropic with $\mathrm{E}=8 \mathrm{GPa}$ and $v=0.28$. Yan \& Han [19] used effective medium theory and back-calculated Young's modulus of 4.5, 6.42 and 10.7 GPa for immature, mature and over-mature organic matter, respectively; the increase of stiffness with thermal maturity has also been reported by [20]. Eliyahu et al. [21] performed PeakForce QNM and found elastic moduli ranging from $0-25 \mathrm{GPa}$ with a modal value of $15 \mathrm{GPa}$.

The PeakForce QNM results in this study are consistent with the previously reported values of the mechanical properties of kerogen. However, there are differences in the values obtained by different techniques and it is not an easy task to prove which method gives the most accurate values.

\subsection{Nanoindentation testing}

In this test, an indenter with known mechanical properties is pushed into a material with unknown properties. The continuous loading and unloading curves are extracted to determine different mechanical parameters. The indentation is conducted on a grid such that a statistical characterisation of the various material phases is available.

Here, the elastic response is of interest and this is obtained when the indenter is extracted. The initial slope of the unloading curve, $S$, is a purely elastic response and can be related to an indentation (or reduced) modulus by:

$$
M=\beta \frac{\sqrt{\pi}}{2} \frac{S}{\sqrt{A_{c}}}
$$

where $A_{c}$ is the contact area and $\beta$ is a correction factor related to the tip shape.

For each sample, thin sections parallel and perpendicular to the bedding plane were prepared. A high load of $500 \mathrm{mN}$ was applied to capture the overall response of the shale microstructure. The indentation was conducted on a $7 \times 7$ grid with a spacing of $100 \mu \mathrm{m}$ spacing. This is illustrated in Figure 3, which shows the visible indents made by a Berkovich tip.

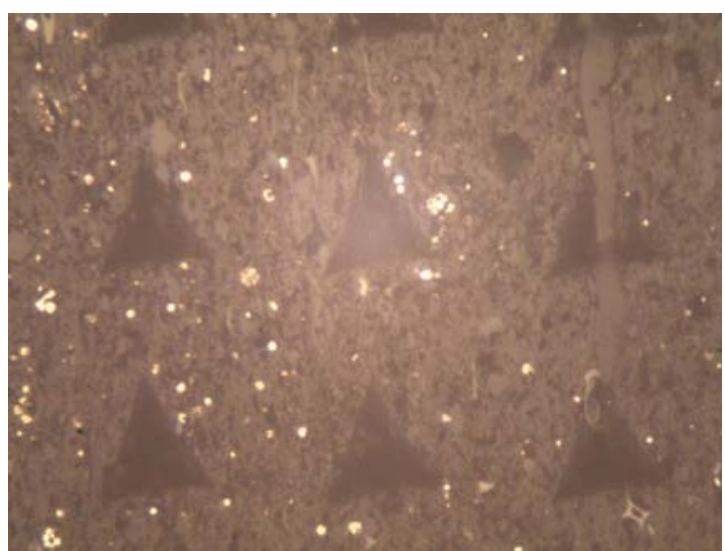

Figure 3. Indentation grid on WIC sample. The spacing between indents is $100 \mu \mathrm{m}$.

Figure 4 shows the load-displacement curves obtained from the indentation grid on the WIC sample. The scatter in the plots indicates the influence of the composite microstructure on the mechanical response. If the contact area was much larger than the size of each individual constituent, the curve would be reproducible. 


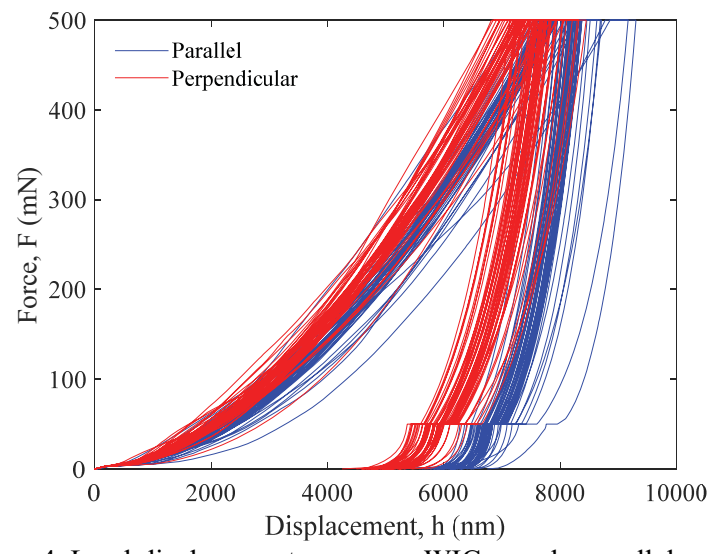

Figure 4. Load-displacement curves on WIC sample, parallel and perpendicular to bedding plane.

The histogram of indentation moduli is shown in Figure 5, again for the WIC sample. It can be seen that the indentation modulus is distributed around a peak. The anisotropy of the sample is evident, with the peak modulus of samples parallel to the bedding plane much higher than in the perpendicular direction. Table 3 presents the mean and standard deviation of the indentation modulus from the different samples.

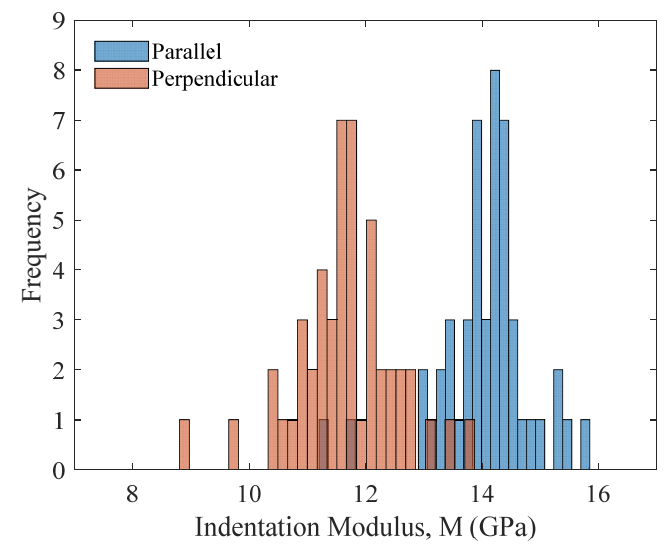

Figure 5. Histogram of indentation modulus on WIC sample.

Table 3. Indentation modulus on Posidonia shale.

\begin{tabular}{|c|c|c|c|c|c|}
\hline \multirow{2}{*}{ Sample } & \multicolumn{2}{|c|}{ M $_{1}$} & \multicolumn{2}{c|}{ M3 } & \multirow{2}{*}{$\begin{array}{c}\text { Anisotropy } \\
\text { (M1/M3) }\end{array}$} \\
\cline { 2 - 5 } & Mean & SD & Mean & SD & \\
\hline WIC & 14.1 & 0.8 & 11.7 & 0.9 & 1.21 \\
\hline HAR & 24.5 & 5.7 & 19.8 & 2.9 & 1.24 \\
\hline HAD & 51.5 & 9.9 & 39.5 & 6.0 & 1.30 \\
\hline
\end{tabular}

\section{Homogenisation of elastic response}

\subsection{Homogenisation methods}

To obtain the macroscopic stiffness tensor of the anisotropic shale composite, linear micromechanics can be used to homogenize the elastic response through various levels [22].

The homogenised stiffness tensor for a composite of $N$ phases can be written:

$$
\mathbb{C}_{\text {hom }}=\sum_{r=0}^{N} f_{r} \mathbb{C}_{r}: \mathbb{A}_{r}
$$

where $f_{r}$ is the volume fraction, $\mathbb{C}_{r}$ is the stiffness tensor and $\mathbb{A}_{r}$ is the strain localisation tensor of the $r$-th phase.

The strain localisation tensor is given by:

$$
\begin{gathered}
\mathbb{A}_{r}=\left[\mathbb{1}+\mathbb{P}_{r}:\left(\mathbb{C}_{r}-\mathbb{C}_{0}\right)\right]^{-1} \\
:\left\{\sum_{s=0}^{N} f_{s}\left[\mathbb{1}+\mathbb{P}_{s}:\left(\mathbb{C}_{s}-\mathbb{C}_{0}\right)\right]^{-1}\right\}^{-1}
\end{gathered}
$$

where $\mathbb{I}$ is the fourth-order identity tensor and $\mathbb{P}_{S}$ is the Hill tensor, closely related to the Eshelby tensor, which is a function of particle shape and orientation.

Two commonly used homogenisation techniques are the Mori-Tanaka (MT) method [23] and the SelfConsistent Scheme (SCS) [24]. For the MT approach, the inclusions are embedded in a matrix phase such that $\mathbb{C}_{0}=\mathbb{C}_{\text {mat }}$, where $\mathbb{C}_{\text {mat }}$ is the stiffness tensor of the matrix. For the SCS, the inclusions are embedded into an homogenised medium, leading to $\mathbb{C}_{0}=\mathbb{C}_{\text {hom }}$; this morphology is described as a granular texture [25], with no phase dominating the composite, in contrast to the matrix-inclusion morphology of the MT scheme.

\subsection{Formulation}

Here, the formulation of the homogenisation scheme follows that of Goodarzi et al. [26]. Shale is assumed to consist of silt inclusions randomly embedded into a clay matrix comprising solid clay, kerogen and pores. The inherent anisotropy of the shale is assumed to originate from the solid unit of clay. The homogenisation therefore takes place at two levels: first, the homogenised properties of the porous clay matrix are obtained; second, the macroscale stiffness tensor is found by inclusion of the silt particles.

\subsubsection{Level I (porous clay matrix)}

At the first level, the overall anisotropy of the shale response is included by assuming a transversely isotropic (TI) stiffness tensor for the solid unit of clay. The five elastic components are taken from Ortega et al. [27] and summarised in Table 3. The Voigt-Reuss-Hill averaged equivalent isotropic stiffness constants of $\mathrm{K}=23.9 \mathrm{GPa}$ and $\mathrm{G}=6.7 \mathrm{GPa}$ agree well with previous studies, e.g. $[14,28]$. However, there is still uncertainty related to the elastic properties of the solid clay that should be adopted 
for homogenisation schemes. Recently, [25] and [29] have back-analysed the TI elastic constants on various shales and found much higher stiffness values, closer to those obtained for individual clay particles [30].

Table 4. Components of TI elastic tensor for solid clay [27].

\begin{tabular}{|c|c|}
\hline Elastic constant & Value (GPa) \\
\hline $\mathrm{C}_{11}$ & 44.9 \\
\hline $\mathrm{C}_{33}$ & 24.2 \\
\hline $\mathrm{C}_{13}$ & 18.1 \\
\hline $\mathrm{C}_{66}$ & 11.6 \\
\hline $\mathrm{C}_{44}$ & 3.7 \\
\hline
\end{tabular}

The porosity of the shale is assumed to exist solely in the porous clay matrix, and so $\phi_{\text {mat }}=\phi_{\text {shale }} / f_{\text {mat }}$ where $f_{\text {mat }}$ is the volume fraction of the matrix components. The elastic properties of kerogen are taken from Table 1. The over-mature HAD sample is assumed to have the same properties as the mature HAR, following the findings of Emmanuel et al. [20] who reported an increase in elastic modulus from immature to mature shales but little change with a further increase in maturity.

Numerical investigation by Goodarzi et al. [31] showed that SCS performs well at homogenisation of the porous clay matrix, and so is adopted here.

\subsubsection{Level II (silt inclusions)}

At the second level, silt particles within the shale composite are included in the homogenisation. The particles are assumed to be spherical and isotropic. The insignificant effect of particle shape on the anisotropic macroscopic response is supported by experimental and modelling studies [32]. The elastic properties are taken from literature and summarised in Table 5.

Table 5. Elastic properties of silt inclusions [14].

\begin{tabular}{|c|c|c|}
\hline Mineral & E (GPa) & v \\
\hline Quartz & 101 & 0.06 \\
\hline Calcite & 95 & 0.28 \\
\hline Pyrite & 265.4 & 0.18 \\
\hline Feldspar & 73.7 & 0.26 \\
\hline Dolomite & 118 & 0.29 \\
\hline
\end{tabular}

For comparison with the experimental results, the components of the macroscopic stiffness matrix can be related to the indentation moduli $\mathrm{M}_{1}$ and $\mathrm{M}_{3}$ [33]:

$$
\begin{gathered}
M_{3}=2 \sqrt{\frac{C_{11} C_{33}-C_{13}^{2}}{C_{11}}\left(\frac{1}{C_{44}}+\frac{2}{\sqrt{C_{11} C_{33}}+C_{13}}\right)^{-1}} \\
M_{1} \approx \sqrt{\frac{C_{11}{ }^{2}-C_{12}{ }^{2}}{C_{11}} \sqrt{\frac{C_{11}}{C_{33}}} M_{3}}
\end{gathered}
$$

\subsection{Predicted macroscopic response}

The indentation moduli predicted through the two-level homogenisation scheme are compared with the experimental values in Figure 6. The plot shows the mean experimental modulus $+/$ - one standard deviation. The predicted values are bracketed by the range in porosity and TOC, as reported by [13]. The homogenised stiffness is sensitive to these soft phases; the lower bound considers the maximum reported porosity and TOC for each borehole (WIC, HAR or HAD), and vice versa for the upper bound. SCS is used at the first level of homogenisation, with the results of both SCS and MT at the second level shown on the plot.

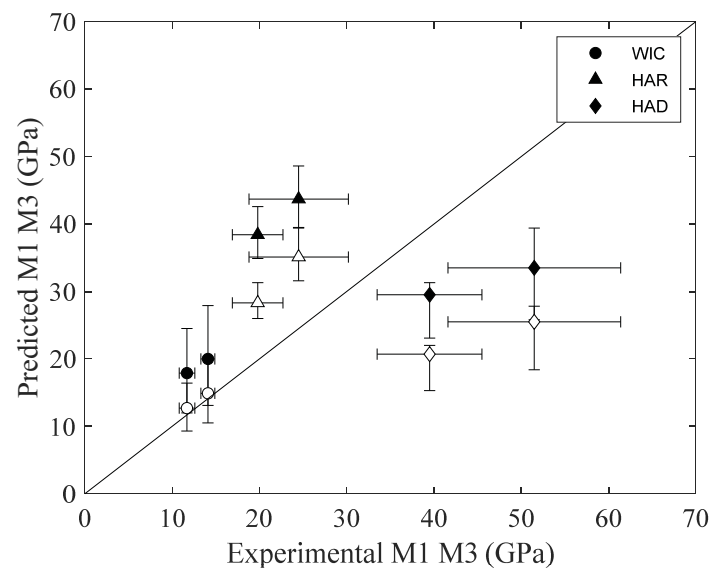

Figure 6. Experimental and predicted indentation moduli. SCS: full, MT: empty.

Figure 6 indicates that the homogenisation is relatively successful in predicting the experimental indentation moduli of the WIC sample but over- and under-estimates the stiffness of HAR and HAD samples respectively. SCS predicts a higher stiffness than MT because, as found by [31] in numerical simulations, the predicted stiffness of the two methods diverges as the volume fraction of silt inclusions increases above $40 \%$, with SCS shown to overestimate the elastic properties of a single-inclusion morphology and MT underestimate.

The volume fractions of silt inclusions are $41 \%, 53 \%$ and $50 \%$ for WIC, HAR and HAD respectively (Table 1). A relatively small number of indentation tests were carried out, and the samples with a higher fraction of silt inclusion showed a higher variability in indentation moduli (see Table 3), particularly the HAD sample, which may contribute to the difficulty in predicting the mechanical response.

Table 6 shows that the homogenisation can predict the anisotropy of the shale response reasonably well, in terms of the ratio of indentation modulus parallel to the bedding 
plane to that in the perpendicular direction. SCS-MT is the more successful, although both schemes fail to predict the higher anisotropy of the HAD sample.

Table 6. Experimental and predicted anisotropy.

\begin{tabular}{|c|c|c|c|}
\hline \multirow{2}{*}{ Sample } & \multicolumn{3}{|c|}{$\begin{array}{c}\text { Anisotropy } \\
\left(\mathbf{M}_{1} / \mathbf{M}_{3}\right)\end{array}$} \\
\cline { 2 - 4 } & Experimental & $\begin{array}{c}\text { SCS- } \\
\text { SCS }\end{array}$ & $\begin{array}{c}\text { SCS- } \\
\text { MT }\end{array}$ \\
\hline WIC & 1.21 & 1.12 & 1.18 \\
\hline HAR & 1.24 & 1.14 & 1.24 \\
\hline HAD & 1.30 & 1.13 & 1.23 \\
\hline
\end{tabular}

Herrmann et al. [34] conducted triaxial compression tests on HAD and HAR samples (perpendicular to the bedding plane) and found elastic modulus values of 6-11 $\mathrm{GPa}$. The lower SCS-MT estimate of elastic modulus from the homogenisation is approximately $26 \mathrm{GPa}$ for HAD and $20 \mathrm{GPa}$ for HAR samples. This suggests that larger-scale features such as microcracks and fractures may influence the mechanical response at triaxial scale.

\section{Conclusions}

In this study, multi-scale mechanical testing was combined with homogenisation techniques to predict the elastic response of Posidonia shale. Using PF-QNM, the elastic properties of kerogen were able to be determined, with clear peaks observable in the histograms of recorded measurements. Nanoindentation testing was also conducted to further constrain the mechanical response of the shale microstructure. Upscaling of the mechanical properties through a two-level homogenisation scheme showed a reasonable prediction of the indentation modulus when compared with the experimental data, including capturing the inherent anisotropy of the shale response. A high volume fraction of silt inclusions appears to present difficulties for homogenisation, which reflects previous findings, e.g. [31]. Comparison of the homogenised elastic modulus with triaxial experiments suggests that at larger scales, features such as microcracks may be important and should be included in the homogenisation scheme.

This research forms part of SHAPE-UK (grant numbers NE/R018057/1 and NE/R017840/1) and the authors would like to thank NERC for financial support.

\section{References}

1. H. Sone, M.D. Zoback, Mechanical properties of shale-gas reservoir rocks - Part 1: Static and dynamic elastic properties and anisotropy, Geophysics 78, D381-D392 (2013)

2. H. Sone, M.D. Zoback, Mechanical properties of shale-gas reservoir rocks - Part 2: Ductile creep, brittle strength, and their relation to the elastic modulus, Geophysics 78, D393-D402 (2013)

3. V. Kumar, C.H. Sondergeld, C.S. Rai, Nano to Macro Mechanical Characterization of Shale, SPE Ann. Tech. Conf. and Exhb., SPE-159804-MS (2012)

4. A.C. Aplin, J.H.S. Macquaker, Mudstone diversity: Origin and implications for source, seal, and reservoir properties in petroleum systems, AAPG Bull. 95, 2031-2059 (2011)

5. E. Rybacki et al., What controls the mechanical properties of shale rocks? - Part I: Strength and Young's modulus, J. Petrol. Sci. Eng. 135, 702-722 (2015)

6. Y. Abousleiman et al., GeoMechanics Field Characterization of the Two Prolific U.S. Mid-West Gas Plays with Advanced Wire-Line Logging Tools, SPE Ann. Tech. Conf. and Exhb., SPE-124428-MS (2009)

7. F.J. Ulm, Y. Abousleiman, The nanogranular nature of shale, Acta Geotech. 1, 77-88 (2006)

8. C. Bobko, F.J. Ulm, The nano-mechanical morphology of shale, Mech. Mater. 40, 318-337 (2008)

9. J.C. Zeszotarski et al., Imaging and mechanical property measurements of kerogen via nanoindentation, Geochim. Cosmochim. Acta. 68, 4113-4119 (2004)

10. R. Ahmadov et al., Confocal laser scanning and atomic-force microscopy in estimation of elastic properties of the organic-rich Bazhenov Formation, TLE 28, 18-23 (2009)

11. S. Zargari et al., Organic maturity, elastic properties, and textural characteristics of self resourcing reservoirs, Geophysics 78, D223-D235 (2013)

12. T.F.T. Rexer et al., High-Pressure Methane Adsorption and Characterization of Pores in Posidonia Shales and Isolated Kerogens, Energy Fuels 28, 2886-2901 (2014)

13. E.J. Mathia et al., Influence of Clay, Calcareous Microfossils, and Organic Matter on the Nature and Diagenetic Evolution of Pore Systems in Mudstones, J. Geophys. Res. Solid Earth 124, 149-174 (2019)

14. G. Mavko, T. Mukerji, J. Dvorkin, The Rock Physics Handbook (Cambridge University Press, 2009)

15. L. Vernik, J. Milovac, Rock physics of organic shales, TLE 30, 318-323 (2011)

16. K.S. Okiongbo, A.C. Aplin, S.R. Larter, Changes in Type II kerogen Density as a Function of maturity: Evidence from the Kimmeridge Clay Formation, Energy Fuels 19, 1564-1583 (2005)

17. Bruker's Application Note \#128 (2012)

18. L. Vernik, A. Nur, Ultrasonic velocity and anisotropy of hydrocarbon source rocks, Geophysics 57, 727735 (1992) 
19. F. Yan, D. Han, Measurement of elastic properties of kerogen, 83 ${ }^{\text {rd }}$ SEG Ann. Meet., 2778-2782 (2013)

20. S. Emmanuel et al., Impact of thermal maturation on nano-scale elastic properties of organic matter in sales, Mar. Petrol. Geol. 70, 175-184 (2016)

21. M. Eliyahu et al., Mechanical properties of organic matter in shales mapped at the nanometer scale, Mar. Petrol. Geol. 59, 294-304 (2015)

22. A. Zaoui, Continuum Micromechanics: Survey, J. Eng. Mech. 128, 808-816 (2002)

23. T. Mori, K. Tanaka, Average stress in matrix and average elastic energy of materials with misfitting inclusions, Acta Metall. 21, 571-574 (1974)

24. R. Hill, A self-consistent mechanics of composite materials, J. Mech. Phys. Solids. 13, 213-222 (1965)

25. S. Abedi, M. Slim, F.J. Ulm, Nanomechanics of organic-rich shales: the role of thermal maturity and organic matter content on texture, Acta Geotech. 11. 775-787 (2016)

26. M. Goodarzi et al., Predicting the elastic response of organic-rich shale using nanoscale measurements and homogenisation methods, Geophys. Prospect. 65, 1597-1614 (2017)

27. J.A. Ortega, F.J. Ulm, Y. Abousleiman, The effect of the nanogranular nature of shale on their poroelastic behaviour, Acta Geotech. 2, 155-182 (2007)

28. B.E. Hornby, L. Schwartz, J. Hudson, Anisotropic effective-medium modeling of the elastic properties of shales, Geophysics 59, 1570-1583 (1994)

29. V. Dubey et al., Multiscale Poromechanical Modeling of Shales Incorporating Microcracks, Rock Mech. Rock Eng. 52, 5099-5121 (2019)

30. Z. Wang, M. Wang, M.E. Cates, Effective elastic properties of solid clays, Geophysics 66, 428-440 (2001)

31. M. Goodarzi, M. Rouainia, A.C. Aplin, Numerical evaluation of mean-field homogenisation methods for predicting shale elastic response, Comput. Geosci. 20, 1109-1122 (2016)

32. J.A. Ortega, F.J. Ulm, Y. Abousleiman, The effect of particle shape and grain-scale properties of shale: A micromechanics approach, Int. J. Numer. Anal. Met. 34, 1124-1156 (2010)

33. A. Delafargue, F.J. Ulm, Explicit approximations of the indentation modulus of elastically orthotropic solids for conical indenters, Int. J. Solids Struct. 41, 7351-7360 (2004)

34. J. Herrmann et al., Deformation Experiments on Bowland and Posidonia Shale-Part I: Strength and Young's Modulus at Ambient and In Situ pc-T Conditions, Rock Mech. Rock Eng. 51, 3645-3666 (2018) 